\title{
ANALISA BEBAN KERJA PADA OPERATOR VISUAL DENGAN PENDEKATAN RECOMMENDED WEIGHT LIMIT (RWL) DI PT. JAPPRO BATAM
}

\author{
M. Ansar Bora ${ }^{1}$, Dian Azhari ${ }^{2}$ \\ ${ }^{1}$ Dosen Program Studi Teknik Industri, ${ }^{2}$ Mahasiswa Program Studi Teknik Industri \\ STT IBNU SINA Batam \\ Email : ansar_uim05@yahoo.com
}

\begin{abstract}
ABSTRAK
PT. Jappro Batam yang membuat produk heater, mengalami kenaikan dan penurunan produktivitas. Pada tahun 2013, produktivitas perusahaan adalah sebesar $73 \%$ dan pada tahum 2014 mengalami penurunan menjadi $70 \%$. Salah satu penyebab turunnya produktivitas perusahaan dapat dilihat dari tingkat produktivitas tenaga kerja, dan aktivitas di PT. Jappro 65\% dilakukan oleh tenaga manusia. Salah satu aktivitas yang dilakukan manusia terutama dalam penanganan material (manual material handling) yang dilakukan pada stasiun kerja visual. Pekerjaan yang dilakukan oleh operator visual adalah mengangkat produk heater dengan berat $1 \mathrm{~kg}$ dan melakukan pengecekan terhadap heater. Setelah melakukan wawancara dengan operator pada stasiun kerja tersebut, operator merasakan keluhan sakit di bagian pundak. Jika dibiarkan, maka akan menimbulkan cedera otot rangka. Tujuan penelitian ini adalah untuk mengetahui dan mengukur beban kerja operator visual berdasarkan perhitungan RWL di PT. Jappro Batam.

Adapun metode yang digunakan dalam penelitian ini adalah menentukan nilai RWL (Recommended Weight Limit) dan nilai LI (Lifting Index) untuk mengetahui beban kerja operator visual. Dari penelitian dapat disimpulkan Nilai RWL operator 1 sebesar 7,62 dengan LI sebesar $0,131<1$ artinya berat beban yang diangkat tidak melebihi batas pengangkatan dan tidak mengandung resiko cidera tulang belakang, nilai RWL operator 2 sebesar 7,66 dengan LI sebesar $0,131<1$ artinya berat beban yang diangkat tidak melebihi batas pengangkatan dan tidak mengandung resiko cidera tulang belakang dan Nilai RWL operator 3 sebesar 7,23 dengan LI sebesar 0,138< 1 artinya berat beban yang diangkat tidak melebihi batas pengangkatan dan tidak mengandung resiko cidera tulang belakang.
\end{abstract}

Kata kunci : operator visual, beban kerja, RWL (Recommended Weight Limit), LI (Lifting Index)

\section{PENDAHULUAN}

\subsection{Latar Belakang}

PT. Jappro Batam yang membuat produkheater, dari tahun ke tahun tingkat produktivitas mengalami kondisi turun naik. Pada tahun 2013, produktivitas perusahaan adalah sebesar $73 \%$ dan pada tahum 2014 mengalami penurunan menjadi $70 \%$. Salah satu penyebab turunnya produktivitas perusahaan dapat dilihat dari tingkat produktivitas tenaga kerja, dan aktivitas di PT. Jappro $65 \%$ dilakukan oleh tenaga manusia. Salah satu aktivitas yang dilakukan manusia terutama dalam penanganan material (manual material handling)yang dilakukan pada stasiun kerja visual. Pekerjaan yang dilakukan oleh operator visual adalah mengangkat produk heater dengan berat $1 \mathrm{~kg}$ dan melakukan pengecekan terhadap heater. 
Setelah melakukan wawancara dengan operator pada stasiun kerja tersebut, operator merasakan keluhan sakit di bagian pundak. Jika dibiarkan, maka akan menimbulkan cedera otot rangka.

Untuk mengetahui dan meminimalisasi cedera otot rangka yang terjadi pada pundak tiga orang operator visual, maka penulis tertarik untuk melakukan penelitian untuk menghitung persamaan pembebanan yang disebut Recommended Weight Limit (RWL) yang direkomendasikan oleh NIOSH (National Institute of Occupational Safety and Health), sehingga nantinya bisa menjadi masukan dan saran bagi perusahaan.

\subsection{Rumusan Masalah}

Berdasarkan latar belakang diatas maka dapat dirumuskan permasalahan dalam penelitian ini yaitu bagaimana dan berapa nilai beban kerja operator visual berdasarkan perhitungan RWL di PT. Jappro Batam?

\subsection{Tujuan Penelitian}

Mengetahui dan mengukur beban kerja operator visual berdasarkan perhitungan RWL di PT. Jappro Batam.

\subsection{Manfaat Penelitian}

Adapun hasil penelitian ini memberikan manfaat untuk memberikan masukan kepada perusahaan agar memperhatikan beban kerja dalam pembagian pekerjaan terutama untuk penanganan material secara manual.

\section{METODOLOGI PENELITIAN}

\subsection{Tempat Penelitian}

Penelitian ini dilakukan dari Juni September 2015 yang dilakukan pada operator visual di PT. Jappro

\subsection{Jenis Penelitian}

Data yang dikumpulkan dalam penelitian ini adalah:

1. Data primer adalah data dasar dalam penelitian. Adapun data primer dalam penelitian ini adalah data denyut nadi operator visualpada saar bekerja dan saat istirahat, berat dan tinggi badan, jarak horizontal posisi tangan yang memegang beban dengan titik pusat tubuh $(\mathrm{H})$, Jarak vertikal posisi tangan yang memegang beban terhadap lantai (V), Jarak perpindahan beban secara vertikal antara tempat asal sampai tujuan (D), Sudut simetri putaran yang dibentuk antara tangan dan kaki (A).

2. Data sekunder untuk menunjang penelitian. Adapun yang termasuk data sekunder adalah teori yang berhubungan dengan penelitian yaitu tentang teori Recommended Weight Limit (RWL) dan penelitian-penelitian terdahulu.

\subsection{Metode Pengumpulan Data}

Metode pengumpulan data yang dilakukan adalah:

1. Wawancara

Wawancara dilakukan untuk mengetahui data diri dari masing-masing operator

2. Pengamatan Langsung

Pengamatan langsung dilakukan untuk mengetahui data denyut nadi operator visual pada saar bekerja dan saat istirahat, berat dan tinggi badan, jarak horizontal posisi tangan yang memegang beban dengan titik pusat tubuh $(\mathrm{H})$, Jarak vertikal posisi tangan yang memegang beban terhadap lantai (V), Jarak perpindahan beban secara vertikal antara tempat asal sampai tujuan (D), Sudut simetri putaran yang dibentuk antara tangan dan kaki (A). Pengukuran denyut nadi operator dilakukan dengan metode jam henti.

\subsection{Metode Pengolahan Data}

Pengolahan data dilakukan menggunakan pendekatan RWL, dengan tahapan perhitungan sebagai berikut:

1. Penilaian RWL dengan pendekatan fisiologis secara tidak langsung dengan tahapan perhitungan sebagai berikut :

a. Penilaian metabolisme tubuh secara tidak langsung dengan metode 10 denyutan (kilbon, 1992 dalam Widodo, S 2008 dalam Soleman, 2011).

b. Perhitungan peningkatan denyut nadi yang diekspresikan dalam persentase. 
c. Penentuan klasifikasi beban kerja berdasarkan peningkatan denyut nadi kerja.

2. Penilaian RWL dengan pendekatan fisiologis secara langsung dengan tahapan perhitungan sebagai berikut :
a. Perhitungan metabolisme basal menurut Mahan.
b. Menghitung luas permukaan tubuh berdasarkan teori Aud dan Du Bois.
c. menentukan konsumsi energi kerja.

3. Perhitungan Recommended Weigt Limit.

4. Penentuan faktor pengali berdasarkan sikap dan kondisi kerja pengangkatan beban yaitu :
a. Konstanta pembebanan (LC)
b. Perhitungan nilai HM
c. Perhitungan nilai VM
d. Perhitungan nilai
e. Perhitungan AM
f. Penentuan nilai FM
g. Penentuan nilai $\mathrm{CM}$

5. Penentuan nilai Lifting Indeks

\section{ANALISA DAN PEMBAHASAN}

\subsection{Pengolahan Data}

3.1.1 Berdasarkan Pendekatan RWL (Recommended Weight Limit) dalam pengolahan data RWL, yang ditentukan adalah nilai HM (Horizontal Multiplier), AM (Asymetric Multiplier), DM (Distance Multiplier) dan VM (Vertical Multiplier).

\section{A. Perhitungan HM (Horizontal Multiplier)}

Nilai HM untuk responden 1 adalah sebesar 0,714, responden 2 sebesar 0,74 dan responden 3 sebesar 0,67 . Contoh perhitungan untuk HM responden 1 yaitu :

$\mathrm{HM}=25 / \mathrm{H}=25 / 35=0,714$.

\section{B. Perhitungan AM (Asymetric Multiplier)}

Nilai AM untuk responden 1 adalah sebesar 0,88, responden 2 sebesar 0,87 dan responden 3 sebesar 0,89. Contoh perhitungan untuk AM responden 1 yaitu :

$$
\begin{aligned}
& \quad \mathrm{AM}=1-(0,0032 \times \mathrm{A})=1-(0,0032 \times 37) \\
& =0,88 \\
& \text { C. Perhitungan DM (Distane Multiplier) }
\end{aligned}
$$

Nilai DM untuk responden 1, 2 dan 3 adalah sebesar 0,88 . Contoh perhitungan untuk DM responden 1 yaitu :

$\mathrm{DM}=0,82+(4,5 / \mathrm{D})=0,82+(4,5 / 70)$ $=0,88$

D. Perhitungan VM (Vertical Multiplier)

Nilai VM untuk responden 1 adalah sebesar 0,84, responden 2 sebesar 0,83 dan responden 3 sebesar 0,83 . Contoh perhitungan untuk VM responden 1 yaitu :

$$
\mathrm{VM}=1-(0,003 \mid \mathrm{V}-75 \vDash 1-(0,003 \text { 20- } 75 \mid
$$
$=0,84$

\subsection{Perhitungan Nilai RWL Responden}

Nilai RWL dihitung untuk masing-masing responden, dengan beberapa unsur sebagai berikut :

Nilai LC (Load Constant) $\quad=23$

Nilai FM (Frequency Multiplier) $=0,75$ untuk frekuensi pengangkatan $1 \mathrm{x}$ permenit selama 8 jam (berdasarkan Tabel 2.4)

Nilai CM (Coupling Multiplier) $=0,95$ termasuk kategori fair untuk $\mathrm{V}<30$ inchi (berdasarkan Tabel 2.5).

Setelah semua unsur diperoleh, kemudian ditentukan nilai RWL sebagai berikut :

RWL responden $1=23 \times 0,714 \times 0,88 \times 0,88$ x 0,84 × $0,75 \times 0,95=7,62$

RWL responden $2=23 \times 0,74 \times 0,87 \times 0,88 \times$ $0,82 \times 0,75 \times 0,95=7,66$

RWL responden $3=23 \times 0,67 \times 0,89 \times 0,88 \times$ $0,83 \times 0,75 \times 0,95=7,23$

\subsection{Perhitungan Nilai LI (Lifting Index) Responden}

Nilai LI (Lifting Index) dihitung dengan membandingkan antara beban angkat dengan nilai RWL. Berat heater yang dihasilkan PT. Jappro Batam adalah sebesar $1 \mathrm{~kg}$, sehingga perhitungan nilai LI untuk masing-masing responden adalah sebagai berikut :

LI responden $1=1 / 7,62=0,131$

LI responden $2=1 / 7,66=0,131$

$\mathrm{LI}$ responden $3=1 / 7,23=0,138$

\section{Analisa Pembahasan}

4.1. Pembahasan 
Analisa beban kerja untuk masing-masing responden dilakukan dengan pendekatan RWL (Recommended Weight Limit) dan LI (Lifting Index).

\subsubsection{Analisa Posisi Pengangkatan Heater}

Heater yang diproduksi oleh PT. Jappro Batam dengan berat sebesar $1 \mathrm{~kg}$, jika diangkat oleh operator visual dalam jumlah yang sering dalam waktu 8 jam bekerja juga akan menimbulkan kelelahan bagi operator. Jika hal ini dilakukan secara terus menerus akan menimbulkan cedera otot bagi operator.

Operator visual memindahkan heater dari meja ke dalam box (kotak) dalam posisi membungkuk. Hal ini akan menimbulkan keluhan sakit dan nyeri pada bagian punggung, pinggang dan tangan. Untuk lebih jelasnya dapat dilihat dari Gambar 4.1.

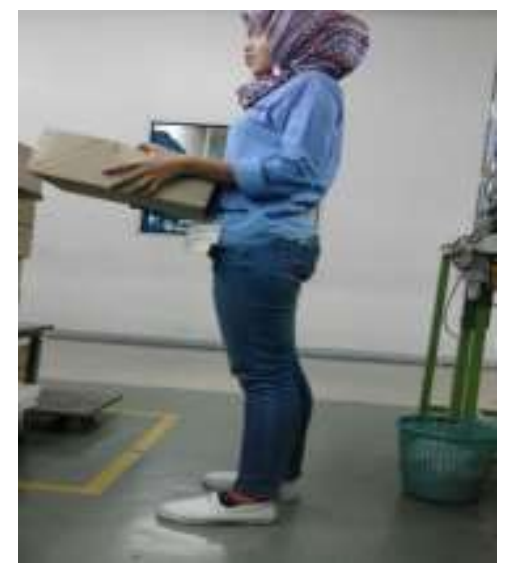

Gambar 4.1

\section{Posisi Awal Pengangkatan Aktivitas Operator Visual}

Untuk menentukan beban kerja operator visual ditentukan dengan RWL (Recommended Weight Limit). Untuk menentukan nilai RWL, ditentukan terlebih dahulu nilai $\mathrm{H}, \mathrm{A}, \mathrm{D}$ dan $\mathrm{V}$. $\mathrm{H}$ menunjukan jarak antara tangan dengan titik tengah pergelangan kaki terhadap beban dimana nilainya adalah $35 \mathrm{~cm}$ untuk operator $1,34 \mathrm{~cm}$ untuk operator 2 dan $37 \mathrm{~cm}$ untuk operator 3 . Nilai A menunjukan sudut yang menunjukan sejauh mana beban dipindahkan dari depan tubuh ketujuan dimana nilainya $37^{\circ}$ untuk operator $1,40^{\circ}$ untuk operator 2 dan $35^{\circ}$ untuk operator 3. Nilai D menunjukan jarak perpindahan beban secara vertikal antara meja ke tempat kotak dimana nilainya $70 \mathrm{~cm}$ untuk operator 1, 2 dan 3. Nilai V menunjukan jarak vertikal posisi tangan yang memegang beban terhadap lantai terhadap beban dimana nilainya $20 \mathrm{~cm}$ pada operator $1,18 \mathrm{~cm}$ pada operator 2 dan operator 3.

\subsubsection{Analisa Nilai RWL (Recommended Weight Limit)}

RWL menggambarkan berat beban yang direkomendasikan untuk hampir semua pekerja yang sehat bisa mengangkat selama periode waktu (hingga delapan jam) tanpa peningkatan risiko mengangkat terkait nyeri punggung atau cedera Setelah dilakukan perhitungan, berat beban yang diirekomendasikan untuk responden 1 yaitu sebesar 7,62 kg, berat beban yang diirekomendasikan untuk responden 2 sebesar 7,66 kg dan berat beban yang diirekomendasikan untuk responden 3 yaitu sebesar 7,23 kg. Hasil perhitungan nilai RWL untuk masing-masing responden dapat dilihat dari Tabel 4.5.

Tabel 4.5 Nilai RWL Responden

\begin{tabular}{|c|c|}
\hline Operator & RWL \\
\hline 1 & 7,62 \\
\hline 2 & 7,66 \\
\hline 3 & 7,23 \\
\hline
\end{tabular}

\subsubsection{Analisa Nilai LI (Lifting Index)}

Lifting index adalah perkiraan relatif dari stres fisik yang terkait dengan pekerjaan mengangkat manual. Saat besaran LI meningkat, tingkat risiko yang diberikan kepada pekerja meningkat dan untuk meningkatkan pekerja diberikan, dan persentase dari tenaga kerja yang mungkin beresiko akan meningkat seperti risk yang terkait dengan nyeri punggung bawah.

Menurut Water, et al, dalam Soleman (2011), jika LI > 1, berat beban yang diangkat melebihi batas pengangkatan yang direkomendasikan maka aktifitas tersebut mengandung resiko cidera tulang belakang. Sedangkan jika LI $<1$, berat beban yang diangkat tidak melebihi batas pengangkatan 
yang direkomendasikan maka aktifitas tersebut tidak mengandung resiko cidera tulang belakang.

Untuk aktivitas visual yang dilakukan di PT. Jappro Batam, nilai LI untuk responden 1 adalah sebesar 0,131 , responden 2 sebesar 0,131 dan responden 3 sebesar 0,138 . Nilai LI ketiga responden adalah kecil dari $1(<1)$ artinya berat beban yang diangkat tidak melebihi batas pengangkatan yang direkomendasikan maka aktifitas tersebut tidak mengandung resiko cidera tulang belakang.

Tabel 4.6 Nilai LI Responden

\begin{tabular}{|c|c|}
\hline Operator & LI \\
\hline 1 & 0,131 \\
\hline 2 & 0,131 \\
\hline 3 & 0,138 \\
\hline
\end{tabular}

\subsubsection{Usulan Perbaikan}

Meskipun nilai LI (Lifting index) untuk masing-masing operator visual $<1$ dan tidak menimbulkan resiko cedera, namun tindakan perbaikan tetap perlu dilakukan. Adapun usulan perbaikan yang dapat dilakukan adalah

1. Menganalisa tata letak stasiun kerja visual

2. Mengubah tata letak pada stasiun kerja visual

3. Menambahkan alat bantu pada stasiun kerja visual

4. Mengubah posisi pengangkatan operator visual

\section{PENUTUP}

\subsection{Kesimpulan}

Dari hasil penelitian, dapat disimpulkan beban kerja operator visual PT. Jappro Batam adalah :

a. Nilai RWL operator 1 sebesar 7,62 dengan LI sebesar $0,131<1$ artinya berat beban yang diangkat tidak melebihi batas pengangkatan dan tidak mengandung resiko cidera tulang belakang. b. Nilai RWL operator 2 sebesar 7,66 dengan LI sebesar $0,131<1$ artinya berat beban yang diangkat tidak melebihi batas pengangkatan dan tidak mengandung resiko cidera tulang belakang.

c. Nilai RWL operator 3 sebesar 7,23 dengan LI sebesar $0,138<1$ artinya berat beban yang diangkat tidak melebihi batas pengangkatan dan tidak mengandung resiko cidera tulang belakang.

\subsection{Saran}

Saran yang dapat diberikan dalam penelitian ini adalah :

1. Walaupun saat ini beban kerja operator visual masih dalam kategori aman, namun masih bisa dipertimbangkan untuk melakukan perbaikan dalam tata letak

2. Penelitian selanjutnya untuk perhitungan beban kerja operator dapat dihitung dengan metode lain sehingga dapat memperkuat hasil penelitian ini.

\section{DAFTAR PUSTAKA}

Nurmianto, E. 1(996). Ergonomi Konsep Dasar dan Aplikasinya. Surabaya : ITS

Prassetyo, H. (2010). Analisis Sikap Kerja Operator Pengisian Botol Lithos Dengan Menggunakan Metode Recommended Weight Limit $(R W L)$ (Studi Kasus di PT. Pertamina Unit Produksi Cilacap). Jurnal Seminar Nasional Mesin dan Industri (SNMI 6) 2010 Program Studi Teknik Mesin dan Teknik Industri Jurusan Teknik Mesin Fakultas Teknik Universitas Tarumanegara

Riduwan. (2004). Belajar Mudah Penelitian untuk Guru, Karyawan dan Peneliti Pemula. Bandung : Alfabeta

Sanjaya, A.A (Maret - Agustus 2002). Aplikasi Recommended Wight Limit $(R W L)$ dalam Perbaikan Cara Pengangkatan. Unitas, Vol. 10 No.2

Soleman, A. (Agustus 2011).Analisa Beban Kerja Ditinjau dari Faktor Usia dengan 
ILTEK, Volume 10, Nomor 20, Oktober 2015

Pendekatan Recommended Weight

Limit. Jurnal ARIKA Vol. 05 No. 2 